\title{
Ocorrência de Listeria monocytogenes em queijos coalho e manteiga comercializados fatiados no comércio varejista de Arapiraca - AL
}

\author{
Occurrence of Listeria monocytogenes in cheeses coalho and butter marketed sliced in the retail \\ trade of Arapiraca - AL
}

Ocurrencia de Listeria monocytogenes en quesos de cuajo y mantequilla comercializados fatiados en el comercio minorista Arapiraca - AL

\author{
Alisson Rogério dos Santos Torres \\ ORCID: https://orcid.org/0000-0001-9152-9409 \\ Universidade Federal de Alagoas, Brasil \\ E-mail: alissontorres16@hotmail.com \\ Taynara Farias Teixeira de Santana \\ ORCID: https://orcid.org/0000-0002-1088-5178 \\ Universidade Federal de Alagoas, Brasil \\ E-mail: taynarafarias@hotmail.com \\ Karla Patrícia Chaves da Silva \\ ORCID: https://orcid.org/0000-0002-7286-0566 \\ Universidade Federal de Alagoas, Brasil \\ E-mail: karla@vicosa.ufal.br \\ Sílvio Gomes de Sá \\ ORCID: https://orcid.org/0000-0001-7249-1580 \\ Universidade Federal de Alagoas, Brasil \\ E-mail: silvio.sa@ vicosa.ufal.br \\ Julicelly Gomes Barbosa \\ ORCID: https://orcid.org/0000-0002-3929-2085 \\ Universidade Federal de Alagoas, Brasil \\ E-mail: julicelly.barbosa@ hotmail.com \\ Oscar Boaventura Neto \\ ORCID: https://orcid.org/0000-0002-5064-861X \\ Universidade Federal de Alagoas, Brasil \\ E-mail: oscar.boaventura@ vicosa.ufal.br
}

\begin{abstract}
Resumo
Objetivou-se verificar a ocorrência de L. monocytogenes, bem como caracterizar o perfil microbiológico de queijos coalho e de manteiga comercializados fatiados no comércio varejista do município de Arapiraca - AL. Foram colhidas 60 amostras de queijos em estabelecimentos varejistas, entre agosto e dezembro de 2018. Foram realizadas Pesquisa de Listeria spp., Determinação do NMP de Coliformes a $45^{\circ} \mathrm{C}$ e Contagens de Mesófilos e Psicrotróficos. Detectou-se a presença de Listeria monocytogenes em duas amostras, posteriormente confirmadas através de qPCR. Em relação ao NMP de Coliformes a $45^{\circ}, 83,3 \%$ (25/30) das amostras de queijo coalho e $80 \%$ (24/30) das amostras de queijo manteiga encontravam-se acima do limite. As contagens de mesófilos em amostras de queijos manteiga variaram entre $1 \times 10^{3}$ e $6 \times 10^{5}$ e entre $1 \times 10^{3}$ e $1,24 \times 10^{7}$ UFC/g em queijos coalho. Os valores obtidos na análise de microrganismos psicrotróficos variaram entre $1 \times 10^{3}$ e $3,4 \times 10^{5}$ em queijos coalho e entre $1 \times 10^{3}$ e $2 \times 10^{5}$, em queijos manteiga. A L. monocytogenes ocorre em queijos coalhos comercializados fatiados em estabelecimentos varejistas de Arapiraca - AL e as condições higiênico-sanitárias inadequadas durante a cadeia produtiva desses queijos representam um risco à saúde pública.
\end{abstract}

Palavras-chave: Listeria monocytogenes; Queijos fatiados; Comércio varejista.

\section{Abstract}

The objective of this study was to verify the occurrence of L. monocytogenes, as well as to characterize the microbiological profile of sliced cheeses and of butter marketed in the retail trade of the municipality of ArapiracaAL. 60 cheese samples were collected in Establishments between August and December 2018. The research of Listeria spp., determination of the NMP of coliforms at $45^{\circ} \mathrm{C}$, and Mesophilic and psyrotrophic counts were performed. The presence of Listeria monocytogenes was detected in two samples, subsequently confirmed by qPCR. In relation to the NMP of Coliformes at $45^{\circ}, 83.3 \%$ (25/30) of the samples of rennet cheese and 80\% (24/30) of the samples of butter cheese were above the limit. The mesophilic counts in butter cheese samples ranged from 1 x $10^{3}$ to 
$6 \times 10^{5}$ and between $1 \times 10^{3}$ and $1.24 \times 10^{7} \mathrm{CFU} / \mathrm{g}$ in Coalho cheeses. The values obtained in the analysis of psychrotrophic microorganisms ranged from $1 \times 10^{3}$ to $3.4 \times 10^{5}$ in cheeses and between $1 \times 10^{3}$ and $2 \times 10^{5}$, in butter cheeses. L. monocytogenes occurs in cheeses sold sliced in stores of Arapiraca - AL and inadequate hygienic-sanitary conditions during the production chain of these cheeses represent a risk to public health.

Keywords: Listeria monocytogenes; Sliced cheeses; Retail trade.

\section{Resumen}

El objetivo de este estúdio fue verificar la ocurrencia de L. monocytogenes, así como caracterizar el perfil microbiológico de los quesos de cuajo e de mantequilla comercializados en rodajas en el comercio minorista del municipio de Arapiraca - AL. Entre agosto y diciembre de 2018 se recogieron 60 muestras de queso en establecimientos comerciales. Se realizaron investigaciones de Listeria spp., determinación del NMP del coliformes a $45^{\circ} \mathrm{C}$ y Recuentos mesofílicos y psicotróficos. Listeria monocytogenes se detectó en dos muestras, posteriormente confirmadas por qPCR. En relación con el NMP de Coliformes a $45^{\circ} \mathrm{C}, 83,3 \%(25 / 30)$ de las muestras de queso de cuajo y $80 \%$ (24/30) de las muestras de queso de mantequilla estaban por encima del límite. Los recuentos mesofílicos en muestras de queso de mantequilla oscilaban entre 1 × $10^{3}$ e $6 \times 10^{5}$ e entre $1 \times 10^{3}$ e 1,24 x $10^{7} \mathrm{UFC} / \mathrm{g}$ en quesos de cuajo. Los valores obtenidos en el análisis de microorganismos psicotróficos variaron entre $1 \times 10^{3}$ e $3,4 \times 10^{5}$ en quesos de cuajo y entre $1 \times 10^{3}$ e $2 \times 10^{5}$, en quesos de mantequilla. La L. monocytogenes ocurre en quesos de cuajo comercializados en rodajas en establecimientos comerciales de Arapiraca - AL y las condiciones higiénicas y sanitarias inadecuadas durante la cadena de producción de estos quesos representan un riesgo para la salud pública.

Palabras clave: Listeria monocytogenes; Queijos en rodajas; Comercio minorista.

\section{Introdução}

Os queijos coalho e manteiga são considerados patrimônios da população nordestina, com grande importância no contexto sociocultural e econômico da região. Devido à simples tecnologia aplicada na elaboração desses queijos, esses produtos são fabricados em larga escala e fazem parte das refeições diárias da população. Sendo assim, o consumo desse produto significa proteger uma cultura e a singularidade de seu ambiente histórico (Dantas, 2013).

A contaminação microbiana de queijos merece atenção ao considerar que bactérias patogênicas são comumente encontradas em derivados lácteos. Vários estudos indicam a contaminação de queijos por microrganismos patogênicos, tais como: S. aureus, E. coli e L. monocytogenes (LM) (Araújo et al., 2017). Segundo Chavada et al., (2014), LM pode causar desde doenças gastrointestinais auto limitantes em pacientes comprometidos imunologicamente, como também meningite, septicemia e aborto. Nesses casos observa-se uma doença febril leve, que pode se agravar dependendo da idade gestacional no momento da infecção (Madjunkov, M., Chaudhry, S., \& Ito, S., 2017).

Surtos de Listeriose estão comumente associados ao consumo de produtos alimentares prontos para o consumo, como por exemplo, o queijo e embutidos cárneos (Heiman et al., 2016), por outro lado, a contaminação dos alimentos com este patógeno pode resultar na sobrevivência e crescimento do microrganismo durante o armazenamento, mesmo em temperaturas de refrigeração devido à sua natureza psicrotrófica (Nassau, et al., 2017).

Em nível mundial, a contaminação por LM em queijos vem sendo discutida por Lahou e Uyttendaele (2017) e Nassau et al. (2017). Esses autores demonstram que essa bactéria possui um potencial de crescimento interno em queijos, e estudam formas de combate com endolisinas para inativá-la. No Brasil, Oxaran et al., (2017) e Prates et al. (2017), apontam o microrganismo como um importante patógeno em queijos de média umidade (46-54,9\%) (Brasil, 1996).

Na região nordeste do Brasil os estudos referentes à LM em queijos coalho e queijos manteiga são escassos, porém, a forma de produção e comercialização adotadas por alguns produtores e comerciantes desses queijos apresentam indícios de possíveis contaminações por este microrganismo, tais como: falta de conhecimento sobre boas práticas de fabricação, condições de exposição para venda do produto e o hábito de fatiá-lo.

Desse modo, objetivou-se verificar a ocorrência de L. monocytogenes, bem como caracterizar o perfil microbiológico de queijos coalho e de manteiga comercializados fatiados no comércio varejista do município de Arapiraca - AL. 


\section{Metodologia}

Foram colhidas aleatoriamente 60 amostras de queijos, sendo 30 de queijo coalho e 30 de queijo manteiga, em estabelecimentos comerciais varejistas, tais como: padarias, mercadinhos e feiras-livres, do município de Arapiraca, estado de Alagoas, entre agosto e dezembro de 2018. Todas as amostras foram fatiadas no estabelecimento comercial e acondicionadas em bandejas de poliestireno cobertas por filme de PVC.

Após a colheita, as amostras foram transportadas em caixas isotérmicas contendo gelo reciclável para o Laboratório de Inspeção de Produtos de Origem Animal do curso de Medicina Veterinária da Universidade Federal de Alagoas - Unidade Educacional Viçosa, onde foram analisadas. As primeiras avaliações realizadas antes das análises microbiológicas foram prazo de validade, a procedência e a condição de exposição para venda dos produtos.

No tocante as análises microbiológicas, utilizando $25 \mathrm{~g}$ de cada amostra, foram realizadas: pesquisa de Listeria spp. e em caso de positividade, realizou-se também a pesquisa para L. monocytogenes. Outros $25 \mathrm{~g}$ de cada amostra foram utilizados para determinação do número mais provável de coliformes a $45^{\circ} \mathrm{C}$, contagem de microrganismos mesófilos e psicrotróficos.

As amostras foram submetidas a pesquisa de Listeria spp. e confirmação de LM conforme os protocolos descritos na ISO 11290-1. Para o isolamento e caracterização das cepas de Listeria spp. foram utilizados métodos fenotípicos, tais como: coloração de gram, catalase, motilidade, $\beta$-hemólise e fermentação de açúcares (xilose e ramnose), originadas de amostras fatiadas no próprio estabelecimento comercial (ISO, 1996; ISO, 2004).

As amostras positivas para L. monocytogenes na série bioquímica foram enviadas ao Laboratório de Análises Veterinárias TECSA LTDA, em Belo Horizonte - MG para execução do método de Reação em Cadeia da Polimerase em Tempo Real Qualitativo (qPCR).

Para a contagem de coliformes foi utilizada a técnica do Número Mais Provável (NMP), conforme protocolo recomendado por Silva, et al., (2007). Para a contagem de microrganismos mesófilos aeróbios estritos e facultativos viáveis e a enumeração de microrganismos psicrotróficos, seguiu-se a metodologia descrita por Silva et al. (2007).

Por fim, nesse estudo de natureza qualitativa (Pereira, et al., 2018) realizou-se análise estatística descritiva simples com as frequências quantificadas como sendo dentro ou fora dos padrões, que foram posteriormente, comparadas à literatura pertinente e com a legislação vigente.

\section{Resultados e Discussão}

As 60 amostras adquiridas provenientes do comércio varejista do município de Arapiraca - AL encontravam-se dentro do prazo de validade, segundo informações contidas no rótulo. Em relação à procedência dos queijos coalho 6,7\% (2/30) apresentavam o selo do Serviço de Inspeção Federal (SIF), 33,3\% (10/30) apresentavam o selo do Serviço de Inspeção Estadual (SIE) e 60\% $(18,30)$ não receberam qualquer tipo de inspeção. Entre os queijos manteiga, 10\% (3/30) possuíam o selo SIF, 36,7\% (11/30) o selo SIE e 53,3\% (16/30) não receberam qualquer tipo de inspeção.

Ao verificar a condição de exposição de venda dos queijos, observou-se que em ambos 46,7\% (14/30) estavam sob temperatura de refrigeração e 53,3\% (16/30) estavam sendo comercializados sob temperatura ambiente.

Dentre as 30 amostras de queijo coalho colhidas, 23,3\% (7/30) apresentaram resultado positivo para a contaminação por Listeria spp. Dessas, 28,5\% (2/7) tiveram positividade confirmada através dos testes bioquímicos para L. monocytogenes. Em relação às amostras de queijo manteiga, 6,7\% (2/30) foram positivas para Listeria spp. As espécies de Listeria identificadas após os testes bioquímicos encontradas nos queijos coalhos analisados encontram-se na Tabela 1. 
Tabela 1. Frequência das espécies de Listeria encontradas em queijos coalho comercializados no município de Arapiraca AL.

\begin{tabular}{cccc}
\hline $\mathbf{N}^{\circ}$ da amostra & Procedência & Exposição de venda (refrigeração) & Espécie \\
\hline 10 & SSI & Temperatura ambiente & L. monocytogenes \\
23 & SSI & Temperatura ambiente & L. monocytogenes \\
4 & SIE & Refrigerado $\left(1\right.$ a $\left.8{ }^{\circ} \mathrm{C}\right)$ & L. welshimeri \\
5 & SSI & Temperatura ambiente & L. welshimeri \\
12 & SSI & Refrigerado $\left(1\right.$ a $\left.8{ }^{\circ} \mathrm{C}\right)$ & L. innocua \\
14 & SSI & Temperatura ambiente & L. innocua \\
6 & SSI & Refrigerado $\left(1\right.$ a $\left.8^{\circ} \mathrm{C}\right)$ & L. ivanovii \\
\hline
\end{tabular}

SSI = Sem Selo de Inspeção; SIE = Selo de Inspeção Estadual.

Fonte: Arquivo pessoal (2019).

Nesta tabela, produzida com os resultados obtidos a partir do isolamento e da caracterização das cepas por testes bioquímicos, observa-se que L. monocytogenes $(28,5 \%)$, L. wilshimeri $(28,5 \%)$ e L. innocua $(28,5 \%)$ apresentaram maior frequência seguidas por L. ivanovii (14,5\%) em queijos coalho. Nos queijos manteiga as amostras positivas eram referentes a uma cepa de L. innocua e outra de $L$. ivanovii.

L. innocua (não patogênica) possui uma taxa de crescimento mais rápida do que a L. monocytogenes (patogênica), tanto durante o enriquecimento através do Caldo Fraser na fase inicial da análise, como durante o isolamento nas placas, tornando o isolamento de L. monocytogenes mais difícil (Park, Chang, Ryu \& Kang, 2014), ou seja, a presença de L. innocua durante o isolamento pode inibir ou tornar mais lento o crescimento de L. monocytogenes.

Há relatos de infecções humanas causadas por L. ivanovii que produziram quadros de gastroenterite e bacteremia em pacientes imunossuprimidos (Guillet, Join-Lambert \& Le Monnier, 2010). Com exceção da LM e de L. ivanovii, nenhuma das outras espécies isoladas são capazes de causar toxinfecções (Karli et al., 2014), mas sugerem uma possível contaminação da área de produção, utensílios, equipamentos e/ou mãos dos manipuladores (Leong et al., 2017).

Foram confirmadas as presenças de L. monocytogenes nas duas amostras submetidas à qPCR. Os iniciadores $L$. monocytogenes utilizados foram projetados para uso específico e exclusivo in vitro e não detecta outras espécies de Listeria. A técnica utilizada possui especificidade e sensibilidade superiores a $95 \%$.

Dos muitos métodos para detectar L. monocytogenes em alimentos, os métodos de cultura continuam sendo o padrão ouro para isolamento e identificação do patógeno (Garrido et al., 2013). Porém, métodos moleculares, como técnicas de PCR são recomendadas para detectar L. monocytogenes devido a sua alta sensibilidade, especificidade e rapidez para a detecção e identificação de L. monocytogenes. No entanto, a sensibilidade, especificidade e detecção da PCR são dependentes dos genesalvo, extração de DNA procedimentos e seqüências iniciadoras utilizadas (Chen, et al., 2017).

Não foram encontrados na literatura estudos que demonstrem casos de listerioses em humanos ocasionados por outras espécies de listeria, com exceção da L. monocytogenes e L. ivanovii. Apesar disso, Rocha et al. (2017), relatam pela primeira vez que células trofoblásticas bovinas são susceptíveis à infecções causadas por L. ivanovii e L. innocua.

Lahou e Uyttendaele (2017), explicam que as oportunidades de contaminação pós-processamento de queijo podem ocorrer em estabelecimentos varejistas de varejo, seja durante o amadurecimento do queijo (até $14^{\circ} \mathrm{C}$ ), durante $\mathrm{o}$ armazenamento e a exposição na refrigeração gabinete (até $7^{\circ} \mathrm{C}$ ) ou durante o fatiamento, principalmente. Para isso, esses autores avaliaram o potencial de crescimento de L. monocytogenes em queijos e verificaram que o microrganismo consegue se desenvolver melhor na superfície de corte dos queijos que dentro. 
Prates et al. (2017), avaliando a qualidade e a segurança microbiológica na produção de queijos de média umidade (46\%), coletaram 24 amostras entre matéria prima, swab das mãos dos manipuladores, e produto final em três laticínios situados na região sul do Rio Grande do Sul, com diferentes níveis de inspeção sanitária. Os resultados obtidos por esses autores não corroboram com a presente pesquisa visto que, não foi verificada a presença de L. monocytogenes nas amostras analisadas.

Oxaran et al. (2017), determinaram a incidência de L. monocytogenes em cinco laticínios e produtos de varejo nas regiões Sudeste e Centro-Oeste do Brasil e observaram que apenas uma amostra $(0,2 \%)$ foi positiva. Segundo os autores, esse resultado pode estar relacionado aos programas de Boas Práticas de Fabricação (BPF) e Análise de Perigos e Pontos Críticos de Controle (APPCC) adotados pela indústria, atendendo às legislações sanitárias.

A presença de L. monocytogenes em alimentos prontos para consumo é bastante preocupante, pois devido as suas características psicrotróficas, resistência à alta concentração de sal e capacidade para sobreviver e crescer em temperaturas que podem variar entre 0 e $45^{\circ} \mathrm{C}$, de forma aeróbica e anaeróbia, em uma ampla gama de $\mathrm{pH}$, que varia de 4,6 a 9,4 (Du et al., 2017), este microrganismo representa um sério problema de saúde pública, haja vista o risco de surtos de listerioses em potencial.

Para Moretro et al. (2017), os queijos são fontes de surtos de listeriose e a principal via de contaminação para $L$. monocytogenes é através da contaminação cruzada entre equipamentos e alimentos durante o processamento, pois a bactéria possui a capacidade de persistir em nichos ambientais, como rachaduras em equipamentos, os quais conferem proteção contra a rotina de higienização.

Não foram encontrados na literatura nacional e internacional trabalhos relacionados à pesquisa de L. monocytogenes em queijos manteiga. Em nosso estudo, 6,6\% (2/30) das amostras foram positivas para pesquisa de Listeria spp. (Tabela 2), as quais após a caracterização por testes bioquímicos verificaram-se que se tratava de uma cepa de $L$. innocua e outra de $L$. ivanovii, ambas sem importância em alimentos (Karli et al., 2014).

Tabela 2. Frequência das espécies de Listeria encontradas em queijos manteiga comercializados no município de Arapiraca AL.

\begin{tabular}{cccc}
\hline $\mathbf{N}^{\circ}$ da amostra & Procedência & Exposição de venda (refrigeração) & Espécie \\
\hline 1 & SIE & Temperatura ambiente & L. innocua \\
2 & SSI & Temperatura ambiente & L. ivanovii \\
\hline
\end{tabular}

SSI = Sem Selo de Inspeção; SIE = Selo de Inspeção Estadual.

Fonte: Arquivo pessoal (2019).

Nesse sentido, o presente resultado foi semelhante ao de Cuevas-González et al. (2017), que também verificaram ausência do microrganismos em amostras de queijo artesanal semelhante ao queijo manteiga em Sonora (México), corroborando assim com esta pesquisa. É válido salientar, que os próprios autores produziram os queijos analisados a fim de explorarem o seu processo de produção, composição química e qualidade microbiológica.

Por outro lado, Oxaran et al. (2017), ao determinarem a prevalência de L. monocytogenes na indústria de laticínios do sudeste e centro-oeste do Brasil, detectaram que 18,8\% (3/16) amostras de queijos Mozzarella comercializados fatiados foram positivas para L. monocytogenes. Os autores sugerem uma possível contaminação cruzada do queijo por esse patógeno durante o fatiamento feito pelos estabelecimentos varejistas, pois não foi observada a presença do micorganismo nas amostras de queijo analisadas ao fim da produção na indústria. 
No Brasil, a legislação vigente, através da Portaria 146/1996 do Ministério da Agricultura Pecuária e Abastecimento (MAPA) (Brasil, 1996) e a Resolução da Diretoria Colegiada - RDC 12/2001 da Agência Nacional de Vigilância Sanitária (Brasil, 2001) estabelece os requisitos microbiológicos para queijos e determina que os produtos de umidade acima de $46 \%$ devem ser isentos desse patógeno.

Observou-se um aumento do número de microrganismos coliformes a $45^{\circ} \mathrm{C}$, mesófilos e psicrotróficos em relação ao tipo sistema de fiscalização atribuído aos queijos, como apresentados na Tabela 3. Vale destacar que a contagem de todos os microrganismos analisados foi maior nos queijos que não dispunham de qualquer tipo de fiscalização sanitária em relação aos queijos inspecionados.

Tabela 3. Médias dos resultados das análises de coliformes a $45^{\circ} \mathrm{C}$, microrganismos mesófilos e psicrotróficos em queijos coalho e manteiga, conforme o tipo de fiscalização.

\begin{tabular}{ccccc}
\hline Tipos de Queijo & Microrganismos & SIF & SIE & SSI \\
\hline \multirow{2}{*}{ Coalho } & Coliformes a 45 ${ }^{\circ} \mathrm{C}\left(\mathrm{NMP} / \mathrm{g}^{*}\right)$ & $1,5 \times 10^{2}$ & $3,8 \times 10^{5}$ & $6 \times 10^{5}$ \\
& Mesófilos (UFC/g**) & $1 \times 10^{3}$ & $1,1 \times 10^{5}$ & $1,1 \times 10^{6}$ \\
& Psicrotróficos (UFC/g**) & $1,3 \times 10^{3}$ & $1 \times 10^{4}$ & $7 \times 10^{4}$ \\
\hline \multirow{2}{*}{ Manteiga } & Coliformes a 45 $5^{\circ} \mathrm{C}\left(\mathrm{NMP} / \mathrm{g}^{*}\right)$ & $1,5 \times 10^{2}$ & $3,4 \times 10^{5}$ & $6,4 \times 10^{5}$ \\
& Mesófilos (UFC/g**) & $1,1 \times 10^{3}$ & $8,7 \times 10^{4}$ & $3,5 \times 10^{5}$ \\
& Psicrotróficos (UFC/g**) & $1,1 \times 10^{3}$ & $1,5 \times 10^{4}$ & $4,1 \times 10^{4}$ \\
\hline
\end{tabular}

*Número Mais Provável por grama/ **Unidade Formadora de Colônia por grama

SIF = Serviço de Inspeção Federal/ SIE = Serviço de Inspeção Estadual $\quad$ SSI = Sem Selo de Inspeção

Fonte: Arquivo pessoal (2019).

$\mathrm{Na}$ tabela acima, destaca-se as altas contagens de Coliformes a $45^{\circ} \mathrm{C}$ e de microrganismos mesófilos e psicrotróficos nas amostras de ambos os tipos de queijo que não apresentavam qualquer tipo de selo de inspeção. No que se refere à determinação do Número Mais Provável de coliformes a $45^{\circ} \mathrm{C}$ em queijos coalho, observou-se uma variação entre 1,5 x $10^{2}$ a valores $>1,1 \times 10^{6} \mathrm{NMP} / \mathrm{g}$ tanto no queijo coalho como no queijo manteiga, havendo diferença apenas em suas médias que foram de $5,6 \times 10^{5}$ e $2,6 \times 10^{5}$, respectivamente.

De acordo com a legislação vigente RDC n 12 (Brasil, 2001), que apresenta o limite de tolerância para coliformes a $45^{\circ} \mathrm{C}$ de $5,0 \times 10^{3} \mathrm{NMP} / \mathrm{g}$ de amostra, 83,3\% (25/30) das amostras de queijo coalho e $80 \%$ (24/30) das amostras de queijo manteiga encontravam-se acima do limite.

Pinto, et al. (2016), fizeram uma avaliação microbiológica de Queijo do Marajó tipo creme, um queijo com características semelhantes ao queijo manteiga, inclusive em sua tecnologia e não observaram contaminação por coliformes nas amostras analisadas. Os autores relacionam esse resultado ao atendimento as exigências do Programa de Qualidade e BPF.

Levando em consideração a presença ou ausência dos selos de inspeção no rótulo de ambos tipos de queijo e a exposição de venda desses produtos no momento da colheita das amostras, observou-se que os maiores valores de coliformes a $45^{\circ} \mathrm{C}$ e microrganismos mesófilos foram encontrados em queijos que possivelmente não receberam qualquer tipo de fiscalização e estavam sendo comercializados em temperatura ambiente.

No tocante a contagem de microrganismos mesófilos em amostras de queijos coalho, foram observadas contagens entre $1 \times 10^{3}$ e $1,24 \times 10^{7} \mathrm{UFC} / g$, com média de $5 \times 10^{5} \mathrm{UFC} / \mathrm{g}$. Evangelista-Barreto, et al. (2016), avaliaram o queijo de coalho da cidade de Cruz das Almas-BA, e verificaram uma contagem média de mesófilos de 5,9 x 10 UFC/g, portanto mais elevada que o presente estudo. Esses autores, relacionam as altas cargas microbianas desses microrganismos no queijo de 
coalho, ao uso da matéria prima de origem não segura, má higienização de utensílios, elaboração sob condições insalubres, e armazenamento e comercialização em temperaturas inadequadas.

As contagens de mesófilos em amostras de queijos manteiga variaram entre $1 \times 10^{3}$ e 6 × $10^{5}$, com média de 7,2 x $10^{4}$ no presente estudo. Esses dados divergem dos resultados de Pinto et al. (2016), que não observaram contaminações por microrganismos mesófilos nas amostras analisadas.

Por outro lado, corrobora com Alexandre, et al. (2016), que avaliaram 40 amostras de queijo manteiga do comércio

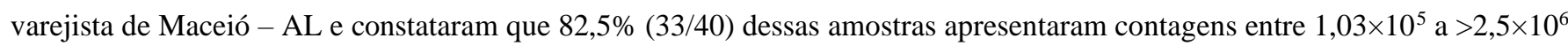
$\mathrm{UFC/g}$. Contagens a partir de $10^{5} \mathrm{UFC/g}$ indicam processamento insatisfatório dando margens à proliferação de patógenos.

Aguilar, et al. (2016), obtiveram contagens de mesófilos entre $1,2 \times 10^{3}$ a $1,1 \times 10^{7} \mathrm{UFC} / \mathrm{g}$ em queijos tipo parmesão ralados no comércio varejista em São Paulo. Esse dado converge com esta pesquisa ao considerar que essa alta carga microbiana possivelmente provém de uma contaminação do produto durante seu fracionamento. De fato, observou-se durante a colheita das amostras que alguns manipuladores não utilizavam Equipamentos de Proteção Individual (EPI), o que sugere uma contaminação cruzada em potencial.

Os valores obtidos na análise de microrganismos psicrotróficos variaram entre $1 \times 10^{3}$ e $3,4 \times 10^{5}$ e média de $9,2 \times 10^{4}$ em queijos coalho e entre $1 \times 10^{3}$ e $2 \times 10^{5}$, com média de $3,2 \times 10^{4}$ em queijos manteiga. Verificou-se ainda, que as maiores contagens de psicrotróficos foram detectadas em amostras que no momento da colheita estavam armazenadas sob refrigeração.

Os microrganismos psicrotróficos além de possuírem a capacidade de se multiplicarem em temperatura de refrigeração são responsáveis por produzirem constantemente enzimas proteolíticas e lipolíticas que alteram a qualidade sensorial no produto mesmo após o processamento, devido à capacidade de termorresistência destas enzimas (Perin, et al., 2012). Desse modo, estes microrganismos podem reduzir o prazo de validade dos queijos.

Rodriguez-López, et al. (2019) alertam que altas contagens de microrganismos psicrotróficos podem estar associadas com a presença de L. monocytogenes, reiterando a importância da análise desses microrganismos em alimentos.

\section{Considerações Finais}

A L. monocytogenes ocorre em queijos tipo coalho comercializados fatiados em estabelecimentos varejistas do município de Arapiraca - AL e sua presença é um indicativo de condições higiênico-sanitárias inadequadas durante a produção, exposição de venda e comercialização desses queijos, especialmente se associada às altas contagens de coliformes, mesófilos e psicrotróficos, representando um risco à saúde pública.

Desse modo, espera-se que novos estudos sejam realizados em outros produtos de origem animal levando em consideração a possibilidade da existência de outros microrganismos patogênicos nesses alimentos, por vezes comercializados clandestinamente em locais insalubres, sem os devidos cuidados.

\section{Referências}

Aguilar, C. E. G., Junior, O. D. R., Vidal, A. M. C., Ribeiro, L. F., \& Rossi, G. A. M. (2016). Microbial quality of industrial and retail market grated parmesan cheese in the State of São Paulo, Brazil. Ciência Rural, 46(12), 2257-2263.

Alexandre, A. P. S., Aquino, A. B., Lyra, D. G., \& Froehlich, A. (2016). Queijo manteiga - contaminação microbiológica e risco à saúde do consumidor. Revista Brasileira de Medicina Veterinária, 38(2):121-124.

Araújo, V. G., Arruda, M. D. O., Duarte, F. N. D., Sousa, J. M. B., Lima, M. C., Conceição, M. L., Schaffner, D. W., \& Souza, E. L. (2017) Predicting and Modelling the Growth of Potentially Pathogenic Bacteria in Coalho Cheese. Journal of Food Protection. 80(7), 1172-1181. João Pessoa.

Brasil. Ministério da Agricultura, Pecuária e Abastecimento. (1996) Portaria n. 146, de 07 de Março de 1996. Regulamentos Técnicos de Identidade e Qualidade dos Produtos Lácteos. Diário Oficial da União, Brasília. 
Brasil. Agência Nacional de Vigilância Sanitária. (2001). Resolução RDC nº 12, de 2 de janeiro de 2001a. Aprova o Regulamento técnico sobre padrões microbiológicos para alimentos. Diário Oficial da União. Brasília.

Chavada, R., Keighley, C., Quadri, S, Asghari, R., Hofmeyr, A., \& Foo, H. (2014). Uncommon manifestations of Listeria monocytogenes infection. BMC Infectious Diseases. 14, 641. Liverpool, Austrália.

Chen, J., Healey, S., Regan, P., Laksanalamai, P., \& Hu, Z. (2017). PCR-based methodologies for detection and characterization of Listeria monocytogenes and Listeria ivanovii in foods and environmental sources. Food Science and Human Wellness. 6, 39-59. Ashland Ave, EUA.

Cuevas-González, P. F., Heredia-Castro, P. Y., Méndez-Romero, J. I., Hérnandez-Mendoza, A., Reyes-Díaz, R., Vallejo-Cordoba, B., \& González-Córdova, A. (2017). Artisanal Sonoran cheese (Cocido cheese): an exploration of its production process, chemical composition and microbiological quality. Journal Science Food Agriculture. 97, 4459-4466.

Dantas, D. S. (2013). Qualidade microbiológica do queijo coalho comercializado no município de Patos, Estado da Paraíba. Revista Agropecuária Científica no Semiárido. 9(3), 110-118.

Du, X., Zhang, X., Wang, X., Su, Y., Li, P., \& Wang, S. (2017) Isolation and characterization of Listeria monocytogenes in Chinese food obtained from the central area of China. Food Control, 74, 9-16.

Evangelista-Barreto, N. S., Santos, G. C. F., Souza, J. S., Bernardes, F. S., \& Silva, I. P. (2016). Queijos artesanais como veículo de contaminação de Escherichia coli e estafilococos coagulase positiva resistentes a antimicrobianos. Revista Brasileira de Higiene e Sanidade Animal, 10(1), 55-67.

Garrido, A., Chapela, M. J., Roman, B., Fajardo, P., Lago, J., Vieites, J. M., \& Cabado, A. G. (2013). A new multiplex real-time PCR developed method for Salmonella spp. and Listeria monocytogenes detection in food and environmental samples. Food Control, 30(1), 76-85.

Guillet, C., Join-Lambert, O., \& Le Monnier, A. (2010). Human Listeriosis Caused by Listeria ivanovii. Emerging Infectious Diseases, 16(1), 136-138.

Heiman, K. E., Garalde, V. B., Gronostaj, M., Jackson, K. A., Beam, S., Joseph, L., Saupe, A., Ricotta, E., Waechter, H., Wellman, A., Adams-Cameron, M., Ray, G., Fields, A., Chen, Y., Datta, A., Burall, L., Sabol, A., Kucerova, Z., Trees, E., Metz, M., Leblanc, P., Lance, S., Griffin, P. M., Tauxe, R. V., \& Silk, B. J. (2016). Multistate outbreak of listeriosis caused by imported cheese and evidence of cross-contamination of other cheeses, USA, 2012. Epidemiology and Infection. 144, 2698-2708. Cambridge.

ISO. (1996). Microbiology of food and animal feeding stuffs - horizontal method for the detection and enumeration of Listeria monocytogenes.-part 1: Detection method (ISO 11290-1:1996)

ISO. (2004a). Microbiology of food and animal feeding stuffs-horizontal method for t detection and enumeration of Listeria monocytogenes.-part 1: Detection Method, Amendment 1:2004. Modification of the Isolation Media and Haemolysys Test (ISO 11290-1:2004).

Karli, A., Sensoy, G., Unal, N., Yanik, K., Cigdem, H., Belet, N., \& Sofuoglu, A. (2014). Ventriculoperitoneal shunt infection with Listeria innocua. Pediatrics International, 56(4), 621-623.

Lahou, E., \& Uyttendaele, M. (2017). Growth potential of Listeria monocytogenes in soft, semi-soft and semihard artisanal cheeses after post-processing contamination in deli retail establishments. Food Control. 76, 13-23.

Leong, D., Nicaogáin, K., Luque-Sastre, L., McManamon, O., Hunt, K., Alvarez-Ordóñez, A., Scollard, J., Schmalenberger, A., Fanning, S., O’Byrne, C., \& Jordan, K. (2017). A 3-year multi-food study of the presence and persistence of Listeria monocytogenes in 54 small food businesses in Ireland. International Journal of Food Microbiology, 249, 18-26.

Madjunkov, M., Chaudhry, S., \& Ito, S. (2017) Listeriosis during pregnancy. Archives of Gynecology and Obstetrics. 296(2), 143-152, Toronto, Canadá.

Moretro, T., Schirmer, B. C. T., Heir, E., Fagerlund, A., Hjemli, P., \& Langsrud, S. (2017). Tolerance to quaternary ammonium compound disinfectants may enhance growth of Listeria monocytogenes in the food industry. International Journal of Food Microbiology. 241, 15-224.

Nassau, T. J. van; Lenz, C. A.; Scherzinger, A. S., \& Vogel, R. F. (2017) Combination of endolysins and high pressure to inactivate Listeria monocytogenes. Food Microbiolgy. 68, 81-88. Freising, Germany.

Oxaran, V., Lee, S. H., Chaul, L. T., Corassin, C. H., Barancelli, G. V., Alves, V. F., Oliveira, C. A. F., Gram, L., \& Martinis, E. C. P. (2017). Listeria monocytogenes incidence changes and diversity in some Brazilian dairy industries and retail products. Food Microbiology. 68, 16-23.

Park, S. H., Chang, P. S., Ryu, S., \& Kang, D. H. (2014) Development of a novel selective and differential medium for the isolation of Listeria monocytogenes. Applied and Environmental Microbiology. 80:1020-1025.

Pereira, A. S., Shitsuka, D. M., Parreira, F. J., \& Shitsuka, R., 2018. Metodologia Da Pesquisa Científica. 1st ed. [ebook] Santa Maria, RS: UAB/NTE/UFSM, pp.67-69. 〈https://repositorio.ufsm.br/bitstream/handle/1/15824/Lic_Computacao_Metodologia-Pesquisa-Cientifica.pdf?sequence=1>

Perin, L. M., Moraes, P. M., Almeida, M. V., \& Nero, L. A. (2012). Interference of storage temperatures in the development of mesophilic, psychrotrophic, lipolytic and proteolytic microbiota of raw milk. Semina - Ciências Agrárias, 33(1), 333-342.

Pinto, M. R. M., Teixeira, M. F., Sarmento, R. C., Neto, G. M., \& Figueiredo, E. L. (2016). Avaliação microbiológica de Queijo do Marajó tipo creme, de leite de búfala, elaborado em queijarias da Ilha do Marajó, Pará. Scientia Plena, 12(06).

Prates, D. F., Würfel, S. R., Goldbeck, J. C., Lima, A. S., Lopes, G. V., \& Silva, W. P. (2017). Microbiological quality and safety assessment in the production of moderate and high humidity cheeses. Ciência Rural, Santa Maria, 47:11.

Rocha, C. E., Mol, J. P. S., Garcia, L. N. N., Costa, L. F., Santos, R. L., \& Paixão, T. A. (2017). Comparative experimental infection of Listeria monocytogenes and Listeria ivanovii in bovine trophoblasts. Plos One. 12(5): e0176911. 
Research, Society and Development, v. 10, n. 1, e26410111775, 2021 (CC BY 4.0) | ISSN 2525-3409 | DOI: http://dx.doi.org/10.33448/rsd-v10i1.11775

Rodríguez-López A. P., Bernárdeza, M., Rodríguez-Herrera, J. J., Comesaña, A. S., \& Cabo, M. L. (2019). Identification and metagenetic characterisation of Listeria monocytogenes-harbouring communities present in food-related industrial environments. Food Control, 95, 6-17.

Silva, N., Junqueira, V. C. A., \& Silveira, N. F. A. (2007). Manual de métodos de análise microbiológica de alimentos. (3a ed.). Livraria Varela. 